\title{
Long-Term Effects of Helicobacter pylori Eradication on Metachronous Gastric Cancer Development
}

\author{
Seung Jun $\mathrm{Han}^{1}$, Sang Gyun Kim${ }^{1}$, Joo Hyun $\mathrm{Lim}^{2}$, Ji Min $\mathrm{Choi}^{2}$, Sooyeon $\mathrm{Oh}^{1}$, Jae Yong Park ${ }^{1}$, Jung Kim ${ }^{1}$, Joo Sung Kim ${ }^{1}$, \\ and Hyun Chae Jung ${ }^{1}$ \\ ${ }^{1}$ Department of Internal Medicine and Liver Research Institute, Seoul National University College of Medicine, and ${ }^{2}$ Department of Internal \\ Medicine and Healthcare Research Institute, Healthcare System Gangnam Center, Seoul National University Hospital, Seoul, Korea
}

\section{See editorial on page 115.}

Background/Aims: Gastric mucosal atrophy and intestinal metaplasia due to Helicobacter pylori infection are the main precursor lesions of gastric cancer. The aim of this study was to evaluate the long-term effects of $H$. pylori eradication on the progression of precancerous lesions to metachronous cancer after endoscopic resection of early gastric cancer (EGC). Methods: Patients who underwent endoscopic resection of EGC were retrospectively reviewed. Changes in precancerous lesions and development of metachronous cancer were compared according to $H$. pylori eradication and final infection status. Results: In total, 565 patients were followed for over 5 years after endoscopic resection of EGC. The grade of atrophy on corpus was significantly lower in the $\mathrm{H}$. pylorieradicated group than in the persistent group during followup ( $p=0.029$ ). In patients $<70$ years of age, the cumulative incidence rate of metachronous cancer was significantly lower in the $\mathrm{H}$. pylori-eradicated group than in the persistent group ( $p=0.018)$. Age was an independent risk factor for metachronous cancer development. Conclusions: $H$. pylori eradication might prevent the development of metachronous cancer in patients $<70$ years of age by delaying the progression of precancerous lesions after endoscopic resection of EGC. (Gut Liver 2018;12:133-141)

Key Words: Helicobacter pylori; Stomach neoplasms; Atrophy; Metaplasia

\section{INTRODUCTION}

Gastric cancer is the fourth most common cause of cancer-related deaths worldwide. ${ }^{1}$ Early gastric cancer (EGC) is defined as a malignancy that does not invade deeper than the submucosa, irrespective of lymph node involvement (T1, any N). Endoscopic submucosal dissection (ESD) for EGC has been widely accepted as a standard treatment in Korea and Japan. However, periodic surveillance is necessary for detection of metachronous cancers even after curative ESD.,3

Helicobacter pylori infection results in gastric mucosal atrophy, intestinal metaplasia, dysplasia, and ultimately, cancer. Mucosal atrophy and intestinal metaplasia have been considered as precancerous lesions; ${ }^{4}$ however, whether precancerous lesions can be reversed by $H$. pylori eradication has not been fully clarified. Some systematic reviews reported that $H$. pylori eradication resulted in significant improvement of mucosal atrophy, whereas improvement of intestinal metaplasia was not seen. ${ }^{5-7}$ However, other recent studies reported a correlation between $H$. pylori eradication and improvement of intestinal metaplasia as well as mucosal atrophy. ${ }^{8-10}$

Whether the eradication of $H$. pylori could prevent the development of metachronous cancer after endoscopic resection of EGC is controversial. In a 3-year prospective study, it was reported that the eradication of $H$. pylori after endoscopic resection of EGC prevented the development of metachronous cancer. ${ }^{11}$ A meta-analysis showed that $H$. pylori eradication was successful in reducing the rate of metachronous gastric cancers. $^{12}$ However, we reported that $H$. pylori eradication did not reduce the incidence of metachronous gastric lesions during a median follow-up period of 3 years after endoscopic treatment of EGC in a prospective randomized manner. ${ }^{13}$ Another study

\footnotetext{
Correspondence to: Sang Gyun Kim

Division of Gastroenterology, Department of Internal Medicine and Liver Research Institute, Seoul National University College of Medicine, 101 Daehak-ro, Jongno-gu, Seoul 03080, Korea

Tel: +82-2-740-8112, Fax: +82-2-743-6701, E-mail: harley1333@hanmail.net

Received on February 14, 2017. Revised on April 26, 2017. Accepted on May 16, 2017. Published online October 27, 2017

pISSN 1976-2283 eISSN 2005-1212 https://doi.org/10.5009/gnl17073

(@) This is an Open Access article distributed under the terms of the Creative Commons Attribution Non-Commercial License (http://creativecommons.org/licenses/by-nc/4.0) which permits unrestricted non-commercial use, distribution, and reproduction in any medium, provided the original work is properly cited.
} 
reported that the eradication of $H$. pylori did not prevent metachronous lesions, although $H$. pylori was a risk factor for the development of metachronous cancer after a median follow-up period of 39 months. ${ }^{14}$ Very few studies with a follow-up period longer than 5 years were conducted.

The aim of this study was to evaluate the long-term effect of $H$. pylori eradication on the progression of precancerous lesions to metachronous cancer after ESD for EGC.

\section{MATERIALS AND METHODS}

\section{Study population and endoscopic examination}

Patients who underwent ESD for EGC between April 2005 and February 2011 were retrospectively reviewed at Seoul National University Hospital. Indications for ESD included differentiated adenocarcinoma, tumor confined to the mucosa, gross tumor size no more than $2 \mathrm{~cm}$ in diameter, and no evidence of distant metastasis. Patients were excluded from the analysis, if (1) they had a prior history of gastric cancer; (2) information was not available for $H$. pylori infection at the time of ESD; (3) there were no additional biopsy samples for the evaluation of precancerous lesions; (4) they had a recurring or synchronous lesion within 12 months after ESD; (5) they had a gastrectomy within 12 months after ESD; (6) they had a follow-up duration less than 12 months; and (7) they were older than 75 years.

The location of the lesions was divided into three portions according to the Japanese Classification of Gastric Cancer: upper, middle, and lower. ${ }^{15}$ In almost all cases, additional biopsy samples were obtained during ESD from two sites in the lesser curvature of the antrum and two sites in the lesser curvature of the corpus to test for the presence of $H$. pylori and to evaluate the histologic grades of gastric mucosal atrophy and intestinal metaplasia using the updated Sydney system. ${ }^{16}$ Rapid urease test (CLO ${ }^{\circledR}$ test; Kimberly-Clark, UT, USA) was also performed at the antrum.

Follow-up endoscopic examination was scheduled at 3, 6, and 12 months and annually thereafter. $H$. pylori status and grades of gastric mucosal atrophy and intestinal metaplasia were evaluated in the same manner at all follow-up examinations. The follow-up data for each participant were reviewed from the baseline exam until the development of metachronous gastric cancer or the last endoscopic exam conducted prior to January 31, 2016.

H. pylori status was considered as positive if at least one test result (rapid urease test or histology) was positive. The patients without $H$. pylori infection during follow-up were classified as the negative group. The patients who underwent $H$. pylori eradication after ESD and confirmed as negative for $H$. pylori during follow-up were defined as the eradicated group, and the patients in whom $H$. pylori were positive during follow-up regardless of whether they underwent $H$. pylori eradication were defined as the persistent group. $H$. pylori eradication was not randomized in all patients.

Metachronous cancer was defined as the new carcinoma that occurred at another site in the stomach one year after ESD. The study was approved by the Ethics Committee of the Seoul National University Hospital (IRB number: H-1519-082-688) and was conducted in accordance with the Declaration of Helsinki.

\section{Statistical analysis}

Demographic data were compared using the independent ttest or analysis of variance test for variables with a parametric distribution, and Pearson chi-square test or the Fisher exact test to compare the proportions. Changes in the histological grades of gastric mucosal atrophy and intestinal metaplasia were evaluated using the Mann-Whitney $U$ test and Wilcoxon signedrank test. The cumulative incidence of metachronous cancer was calculated using the Kaplan-Meier method, and compared between the groups were performed using the log-rank test. The statistical significance of metachronous cancer development according to variables was evaluated using Cox regression analysis. p-values less than 0.05 were considered to be statistically significant. All statistical analyses were performed using the SPSS version 21.0 (IBM Corp., Armonk, NY, USA).

\section{RESULTS}

\section{Baseline characteristics}

In total, 783 patients were reviewed and 218 were excluded in the analysis; three patients with prior histories of gastric cancers; 20 without the information about the initial $H$. pylori infection; 107 without additional biopsy samples for the evaluation of precancerous lesions; six with recurring or synchronous lesions or additional gastrectomy within 12 months; 44 with follow-up duration less than 12 months; and 75 older than 75 years.

Finally, 565 patients were assessed for eligibility. The median follow-up periods for the negative group (157 patients), eradicated group (212 patients), and persistent group (196 patients) were 60, 61, and 60 months (range, 12 to 122 months), respectively. There were no significant differences among the groups in age, sex, location, size, depth of invasion, and tumor differentiation. The proportion of patients with corpus mucosal atrophy was significantly lower in the negative group than the eradicated and the persistent groups $(p=0.020)$. However, the proportion of patients with antral mucosal atrophy and intestinal metaplasia in both the antrum and corpus did not differ among the groups (Table 1).

\section{Changes in gastric mucosal atrophy and intestinal meta- plasia}

Approximately $70 \%$ of patients had antral mucosal atrophy at the time of ESD. There were no significant differences in the proportion of patients with antral mucosal atrophy among the 
Table 1. Baseline Characteristics

\begin{tabular}{|c|c|c|c|c|}
\hline Variable & Negative group & Eradicated group & Persistent group & p-value \\
\hline Total & 157 & 212 & 196 & \\
\hline Age, yr & $62.9 \pm 8.1$ & $61.1 \pm 8.1$ & $61 \pm 9$ & 0.068 \\
\hline Sex & & & & 0.081 \\
\hline Male & $131(83.4)$ & 165 (77.8) & $144(73.5)$ & \\
\hline Female & $26(16.6)$ & $47(22.2)$ & $52(26.5)$ & \\
\hline Location of tumor & & & & 0.380 \\
\hline Upper third & $4(2.5)$ & $9(4.2)$ & $10(5.1)$ & \\
\hline Middle third & 45 (28.7) & $70(33)$ & $50(25.5)$ & \\
\hline Lower third & $108(68.8)$ & $133(62.7)$ & $136(69.4)$ & \\
\hline Size of tumor, mm & $18.3 \pm 11.4$ & $18.3 \pm 12.5$ & $17.9 \pm 11.9$ & 0.932 \\
\hline Depth of invasion of tumor & & & & 0.481 \\
\hline Lamina propria & $77(49)$ & $97(45.8)$ & $94(48)$ & \\
\hline Muscularis mucosa & $66(42)$ & $90(42.5)$ & $89(45.4)$ & \\
\hline Submucosa & $14(8.9)$ & 25 (11.8) & $13(6.6)$ & \\
\hline Histology of tumor & & & & 0.782 \\
\hline Well differentiated & $90(57.3)$ & $127(59.9)$ & $121(61.7)$ & \\
\hline Moderately differentiated & $62(39.5)$ & $80(37.7)$ & 69 (35.2) & \\
\hline Poorly differentiated & $5(3.2)$ & $4(1.9)$ & $4(2.0)$ & \\
\hline Poorly cohesive & 0 & $1(0.5)$ & $2(1.0)$ & \\
\hline Lauren's classification of tumor & & & & 0.712 \\
\hline Intestinal & $152(96.8)$ & $209(98.6)$ & $189(96.4)$ & \\
\hline Diffuse & $3(1.9)$ & $2(0.9)$ & $4(2.0)$ & \\
\hline Mixed & $2(1.3)$ & $1(0.5)$ & $3(1.5)$ & \\
\hline Antral mucosal atrophy & & & & 0.671 \\
\hline None & $38(24.2)$ & $43(20.3)$ & $34(17.3)$ & \\
\hline Mild & $32(20.4)$ & $39(18.4)$ & 39 (19.9) & \\
\hline Moderate & $24(15.3)$ & 38 (17.9) & $40(20.4)$ & \\
\hline Marked & $7(4.5)$ & $9(4.2)$ & $12(6.1)$ & \\
\hline Non-applicable & $56(35.7)$ & $83(39.2)$ & $71(36.2)$ & \\
\hline Corpus mucosal atrophy & & & & 0.020 \\
\hline None & $61(38.9)$ & $52(24.5)$ & $53(27.0)$ & \\
\hline Mild & $22(14.0)$ & $41(19.3)$ & $30(15.3)$ & \\
\hline Moderate & $17(10.8)$ & $39(18.4)$ & $35(17.9)$ & \\
\hline Marked & $11(7.0)$ & $11(5.2)$ & $19(9.7)$ & \\
\hline Non-applicable & $46(29.3)$ & $69(32.5)$ & $59(30.1)$ & \\
\hline Antral intestinal metaplasia & & & & 0.084 \\
\hline None & 25 (15.9) & $32(15.1)$ & 34 (17.3) & \\
\hline Mild & 45 (28.7) & $47(22.2)$ & $52(26.5)$ & \\
\hline Moderate & $62(39.5)$ & $89(42.0)$ & $59(30.1)$ & \\
\hline Marked & $20(12.7)$ & $38(17.9)$ & $45(23.0)$ & \\
\hline Non-applicable & $5(3.2)$ & $6(2.8)$ & $6(3.1)$ & \\
\hline Corpus intestinal metaplasia & & & & 0.429 \\
\hline None & $56(35.7)$ & $66(31.1)$ & $62(31.6)$ & \\
\hline Mild & $33(21.0)$ & $38(17.9)$ & 34 (17.3) & \\
\hline Moderate & $28(17.8)$ & $61(28.8)$ & $52(26.5)$ & \\
\hline Marked & $32(20.4)$ & $42(19.8)$ & 39 (19.9) & \\
\hline Non-applicable & $8(5.1)$ & $5(2.4)$ & $9(4.6)$ & \\
\hline Follow-up duration, mo & $60.0(44.5-74.5)$ & $61.0(49.0-87.8)$ & $60.0(48.0-78.0)$ & \\
\hline
\end{tabular}

Data are presented as mean \pm SD, number (\%), or median (interquartile range). 
A Antral mucosal atrophy at baseline

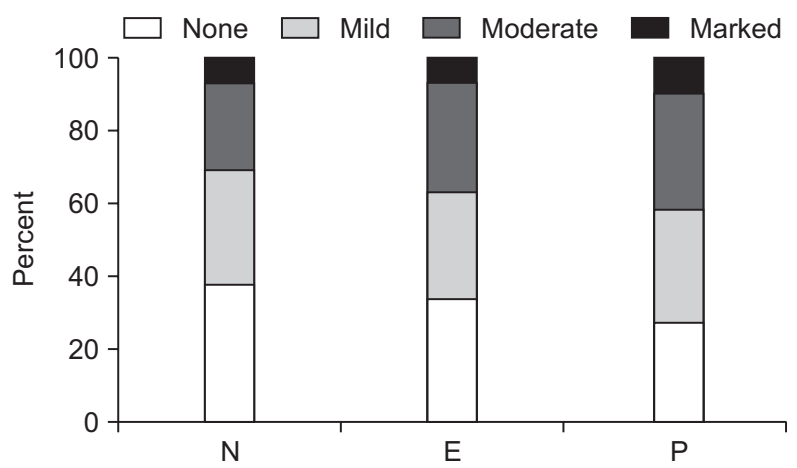

C Corpus mucosal atrophy at baseline

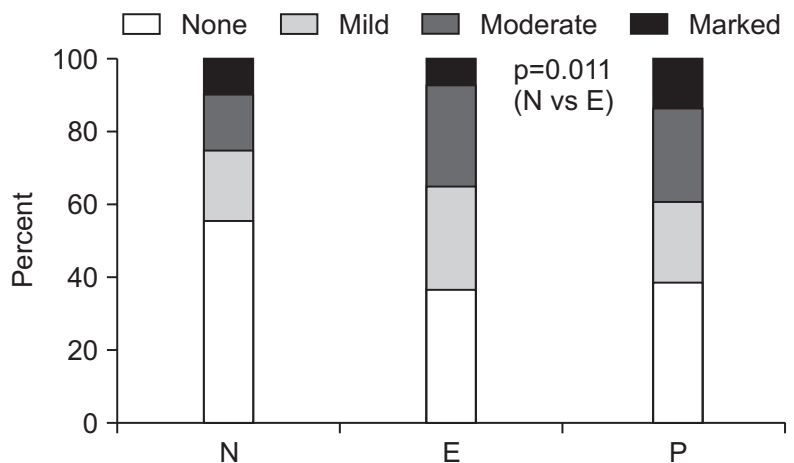

E Antral intestinal metaplasia at baseline

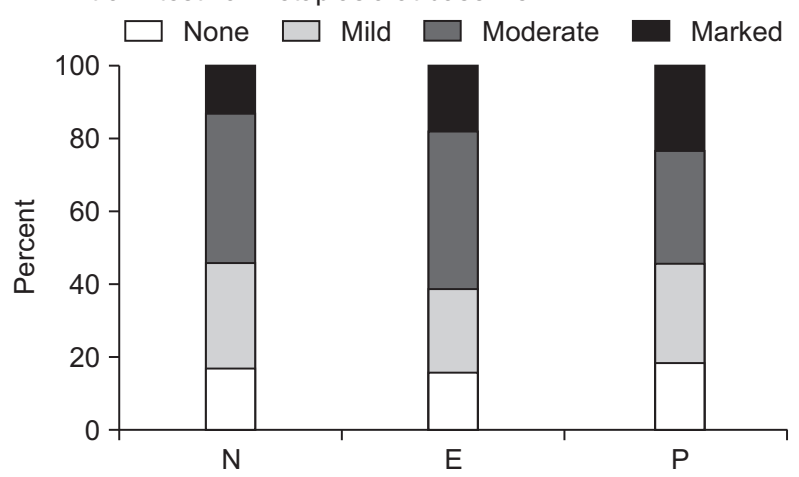

G Corpus intestinal metaplasia at baseline

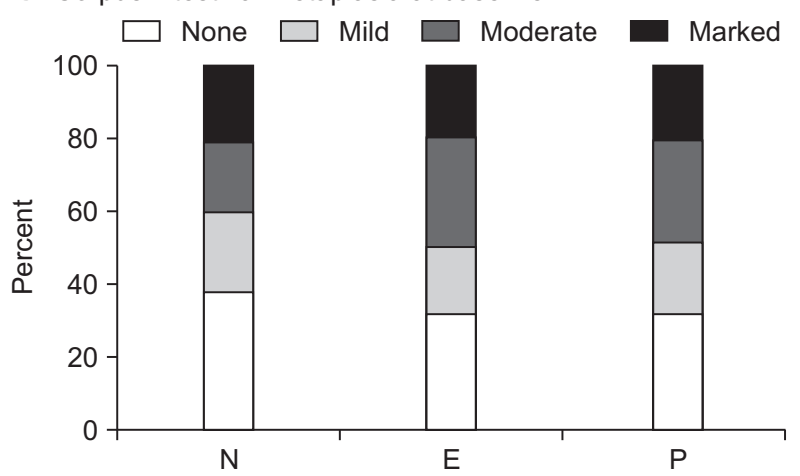

B Antral mucosal atrophy at the last follow-up

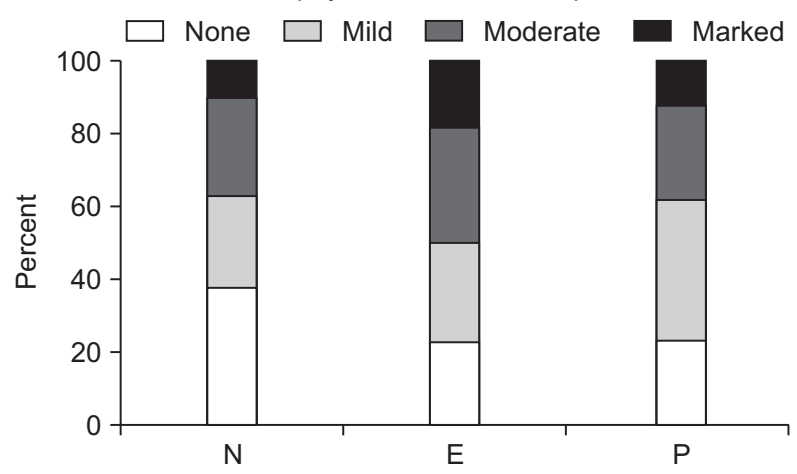

D Corpus mucosal atrophy at the last follow-up

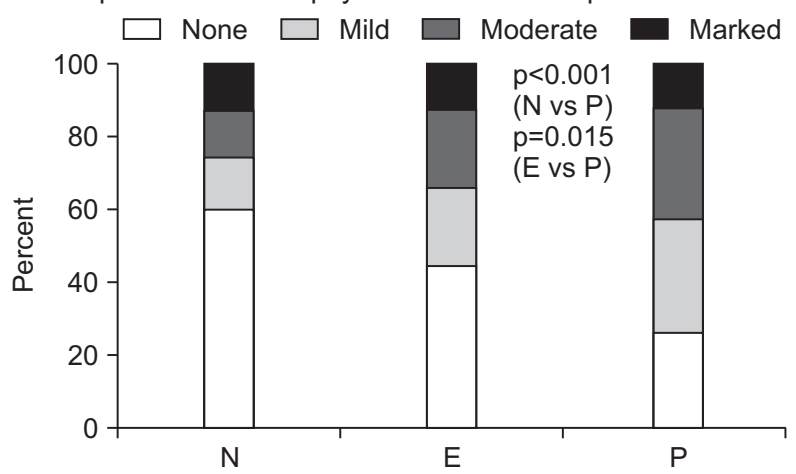

F Antral intestinal mataplasia at the last follow-up

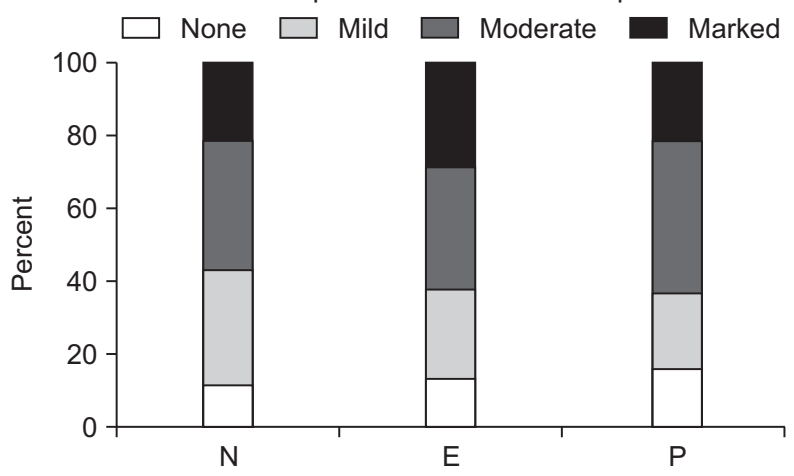

H Corpus intestinal metaplasia at the last follow-up

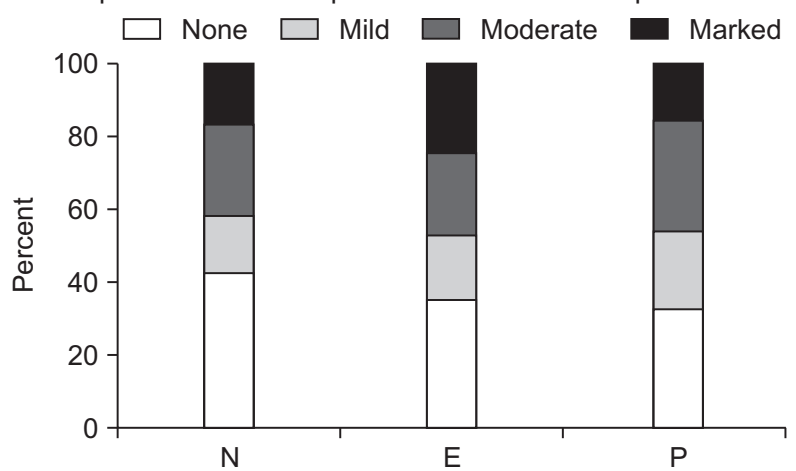

Fig. 1. The proportions of patients with precancerous lesions. (A) Antral mucosal atrophy at baseline. (B) Antral mucosal atrophy at the last follow-up. (C) At baseline, the proportion of patients with corpus mucosal atrophy was higher in the eradicated group than in the negative group $(p=0.011)$. (D) At the last follow-up, the proportion of patients with corpus mucosal atrophy was higher in the persistent group than in the negative and eradicated groups ( $<<0.001$ and $p=0.015$, respectively). (E) Antral intestinal metaplasia at baseline. (F) Antral intestinal metaplasia at the last follow-up. (G) Corpus intestinal metaplasia at baseline. (H) Corpus intestinal metaplasia at the last follow-up. p-values are greater than 0.05 unless otherwise stated.

$\mathrm{N}$, negative group; E, eradicated group; $\mathrm{P}$, persistent group. 
Table 2. Changes in the Average Number of Precancerous Lesions

\begin{tabular}{|c|c|c|c|c|c|c|c|c|}
\hline & \multicolumn{3}{|c|}{ Baseline } & \multirow{2}{*}{$\mathrm{p}$-value } & \multicolumn{3}{|c|}{ The last follow-up } & \multirow{2}{*}{$\mathrm{p}$-value } \\
\hline & $\mathrm{N}$ & $\mathrm{E}$ & $\mathrm{P}$ & & $\mathrm{N}$ & $\mathrm{E}$ & $\mathrm{P}$ & \\
\hline \multicolumn{9}{|c|}{ Mucosal atrophy } \\
\hline Antrum & 1.00 & 1.10 & 1.24 & 0.156 & 1.10 & 1.46 & 1.28 & $0.013(\mathrm{~N}$ vs $\mathrm{E})$ \\
\hline \multirow[t]{2}{*}{ Corpus } & 0.80 & 1.06 & 1.15 & $0.015(\mathrm{~N} \text { vs E) })^{*}$ & 0.79 & 1.03 & 1.29 & $<0.001(\mathrm{~N} \text { vs } \mathrm{P})^{*}$ \\
\hline & & & & $0.009(\mathrm{~N} \text { vs } \mathrm{P})^{*}$ & & & & $0.029(\mathrm{E}$ vs $\mathrm{P})$ * \\
\hline \multicolumn{9}{|c|}{ Intestinal metaplasia } \\
\hline Antrum & 1.51 & 1.65 & 1.61 & 0.357 & 1.68 & 1.78 & 1.69 & 0.492 \\
\hline Corpus & 1.24 & 1.38 & 1.36 & 0.489 & 1.16 & 1.37 & 1.30 & 0.242 \\
\hline
\end{tabular}

Data are presented as mean.

Kruskal-Wallis test. Patients with no precancerous lesion were scored as 0; mild, 1; moderate, 2; and marked, 3 based on the updated Sydney system.

$\mathrm{N}$, negative group; E, eradicated group; $\mathrm{P}$, persistent group.

*Mann-Whitney U test for each pair of groups.

groups during follow-up. The initial proportion of patients with corpus mucosal atrophy did not differ significantly between the eradicated and the persistent group. At the last follow-up, corpus mucosal atrophy was more prominent in the persistent group than the eradicated and the negative groups ( $\mathrm{p}=0.015$ and $p<0.001$, respectively). The proportions of patients with intestinal metaplasia did not differ among the groups during followup (Fig. 1).

Although the mean histological grades for corpus mucosal atrophy did not differ between the eradicated and the persistent groups at baseline, it was significantly lower in the eradicated group than the persistent group at the last follow-up (1.03 vs 1.29 , respectively; $p=0.029$ ). There were no significant differences in the grades of antral mucosal atrophy and intestinal metaplasia in both the antrum and the corpus between the groups during follow-up (Table 2).

\section{Development of metachronous gastric cancer}

During a median follow-up period of 60 months (range, 12 to 122 months), metachronous gastric cancer had developed in 50 patients (50/565, 8.8\%); 20 in the negative group (20/157, $12.7 \%), 12$ in the eradicated group (12/212, 5.7\%), and 18 in the persistent group (18/196, 9.2\%). The incidence of metachronous cancer was lower in the eradicated group than the other groups without statistical significance $(p=0.059)$. The median interval between ESD and the development of metachronous cancer was 36 months in the negative group, 52.5 months in the eradicated group, and 42.5 months in the persistent group. There were no significant differences in the baseline clinicopathologic characteristics of patients with metachronous cancer among the groups (Table 3).

In patients less than 70 years of age, Kaplan-Meier analysis showed that the cumulative incidence rate of metachronous cancer was significantly lower in the eradicated group than the negative and the persistent groups $(p=0.001$ and $p=0.018$, re- spectively) (Fig. 2). In this subgroup, the mean histological grade of corpus mucosal atrophy at baseline was lower in the negative group than the others. At the last follow-up, the mean histological grade of corpus mucosal atrophy of the negative group was lower than that of the persistent group, but not different from that of the eradicated group (Table 4). There were no significant differences in the mean histological grades of precancerous lesions among all groups at baseline and the last follow-up in patients not less than 70 years of age. In subgroup analyses of patients less than 65 years of age, the cumulative incidence rate of metachronous cancer development was consistently lower in the eradicated group than the negative and the persistent group ( $p=0.014$ and $p=0.031$, respectively).

Cox regression analysis showed that the age was an independent risk factor for metachronous cancer development (hazard ratio, 1.059; 95\% confidence interval, 1.001 to $1.120 ; \mathrm{p}=0.045$ ). Sex, grades of precancerous lesions and $H$. pylori status were not significant risk factors for metachronous cancer (Table 5).

\section{DISCUSSION}

This retrospective study aimed to investigate the long-term effect of $H$. pylori eradication on the progression of precancerous lesions to metachronous cancer after ESD for EGC. At the time of ESD, the proportion of patients with corpus mucosal in the eradicated group did not differ from that in the persistent group, and was higher than that in the negative group. This means that corpus mucosal atrophy was milder in the $H$. pylorinegative patients than the $H$. pylori-positive ones. After a median follow-up period of 60 months, the proportion of patients with corpus mucosal atrophy in the eradicated group was lower than that in the persistent, which means $H$. pylori eradication might prevent the progression of corpus mucosal atrophy after ESD for EGC.

On the contrary, the groups did not differ significantly in the 
Table 3. Baseline Characteristics of Patients with Metachronous Cancer

\begin{tabular}{|c|c|c|c|c|}
\hline Variable & Negative group & Eradicated group & Persistent group & $\mathrm{p}$-value \\
\hline Total & 20 & 12 & 18 & \\
\hline Age, yr & $63.9 \pm 7.8$ & $65.3 \pm 8.4$ & $59.6 \pm 8.6$ & 0.135 \\
\hline Sex & & & & 0.822 \\
\hline Male & $19(95)$ & $11(91.7)$ & 16 (88.9) & \\
\hline Female & $1(5)$ & $1(8.3)$ & $2(11.1)$ & \\
\hline Location of tumor & & & & 0.888 \\
\hline Upper third & 0 & 0 & $1(5.6)$ & \\
\hline Middle third & $6(30)$ & $3(25)$ & $6(33.3)$ & \\
\hline Lower third & $14(70)$ & $9(75)$ & $11(61.1)$ & \\
\hline Size of tumor, mm & $17.6 \pm 10.3$ & $23.6 \pm 14.0$ & $17.8 \pm 7.0$ & 0.234 \\
\hline Depth of invasion of tumor & & & & 0.383 \\
\hline Lamina propria & $10(50)$ & $4(33.3)$ & $9(50)$ & \\
\hline Muscularis mucosa & $7(35)$ & $7(58.3)$ & $9(50)$ & \\
\hline Submucosa & $3(15)$ & $1(8.3)$ & 0 & \\
\hline Histology of tumor & & & & 0.620 \\
\hline Well differentiated & $11(55)$ & $5(41.7)$ & $11(61.1)$ & \\
\hline Moderately differentiated & $8(40)$ & $6(50)$ & $7(38.9)$ & \\
\hline Poorly differentiated & $1(5)$ & 0 & 0 & \\
\hline Poorly cohesive & 0 & $1(8.3)$ & 0 & \\
\hline Lauren's classification of tumor & & & & 0.537 \\
\hline Intestinal & $18(95.0)$ & $12(100.0)$ & $18(100.0)$ & \\
\hline Diffuse & $1(2.5)$ & 0 & 0 & \\
\hline Mixed & $1(2.5)$ & 0 & 0 & \\
\hline Antral mucosal atrophy & & & & 0.881 \\
\hline None & $2(10.0)$ & 0 & $2(11.1)$ & \\
\hline Mild & $7(35.0)$ & $4(33.3)$ & $4(22.2)$ & \\
\hline Moderate & $4(20.0)$ & $3(25.0)$ & $4(22.2)$ & \\
\hline Marked & $1(5.0)$ & $1(8.3)$ & $2(11.1)$ & \\
\hline Non-applicable & $6(30.0)$ & $4(33.3)$ & $6(33.3)$ & \\
\hline Corpus mucosal atrophy & & & & 0.087 \\
\hline None & $8(40.0)$ & 0 & $3(16.7)$ & \\
\hline Mild & $2(10.0)$ & $5(41.7)$ & $3(16.7)$ & \\
\hline Moderate & $4(20.0)$ & $2(16.7)$ & $3(16.7)$ & \\
\hline Marked & $1(5.0)$ & $1(8.3)$ & $3(16.7)$ & \\
\hline Non-applicable & $5(25.0)$ & $4(33.3)$ & $6(33.3)$ & \\
\hline Antral intestinal metaplasia & & & & 0.697 \\
\hline None & $2(10.0)$ & $1(8.3)$ & $1(5.6)$ & \\
\hline Mild & $8(40.0)$ & $2(16.7)$ & $5(27.8)$ & \\
\hline Moderate & $5(25.0)$ & $5(41.7)$ & $4(22.2)$ & \\
\hline Marked & $4(20.0)$ & $4(33.3)$ & $7(38.9)$ & \\
\hline Non-applicable & $1(5.0)$ & 0 & $1(5.6)$ & \\
\hline Corpus intestinal metaplasia & & & & 0.770 \\
\hline None & $5(27.8)$ & $1(8.3)$ & $5(29.4)$ & \\
\hline Mild & $4(22.2)$ & $3(25)$ & $2(11.8)$ & \\
\hline Moderate & $6(33.3)$ & $5(41.7)$ & $5(29.4)$ & \\
\hline Marked & $3(16.7)$ & $3(25)$ & $5(29.4)$ & \\
\hline Non-applicable & $2(10.0)$ & 0 & $1(5.6)$ & \\
\hline Follow-up duration, mo & $36.0(25.2-47.0)$ & $52.5(37.8-74.5)$ & $42.5(34.5-84.3)$ & \\
\hline
\end{tabular}

Data are presented as mean $\pm \mathrm{SD}$, number $(\%)$, or median (interquartile range). 

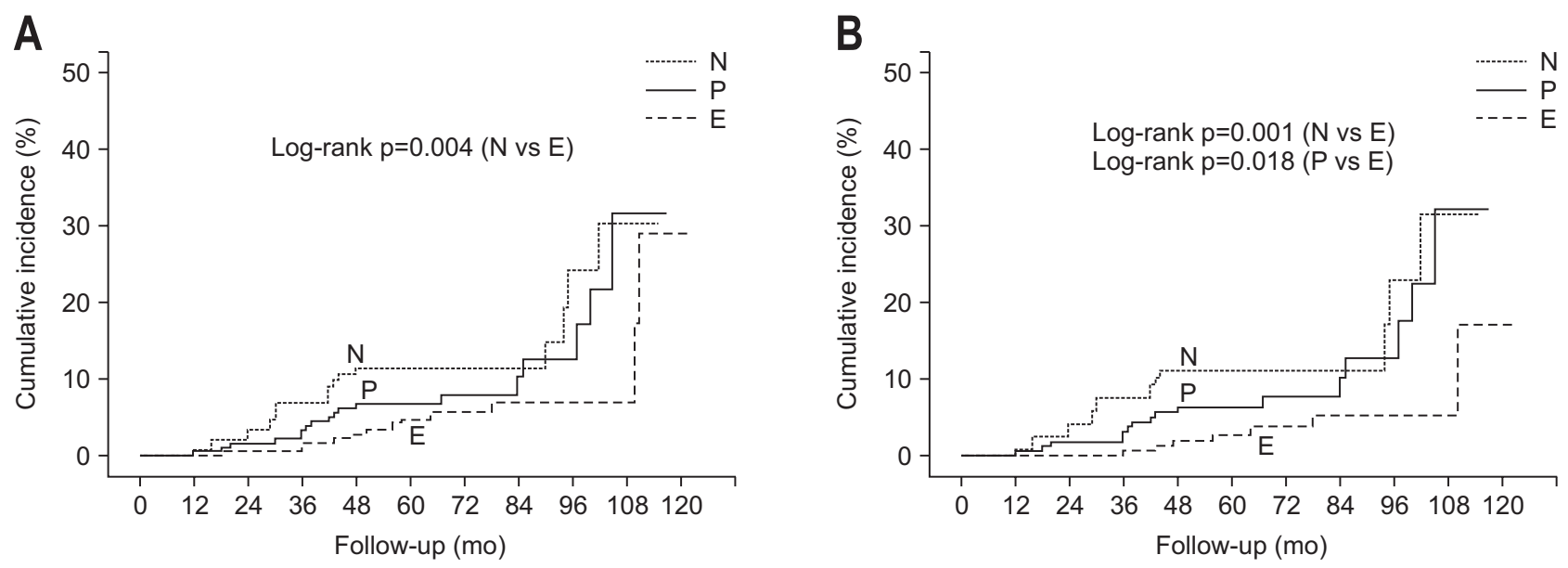

Fig. 2. Cumulative incidence of metachronous cancer. (A) The cumulative incidence rate of metachronous cancer was higher in the negative group than in the eradicated group ( $\mathrm{p}=0.004)$. (B) In patients less than 70 years of age, the cumulative incidence rate of metachronous cancer development was lower in the eradicated group than in the negative and persistent groups ( $p=0.001$ and $p=0.018$, respectively). $p$-values are greater than 0.05 unless otherwise stated.

$\mathrm{N}$, negative group; E, eradicated group; $\mathrm{P}$, persistent group.

Table 4. Changes in the Average Number of Precancerous Lesions in Patients Less Than 70 Years of Age

\begin{tabular}{|c|c|c|c|c|c|c|c|c|}
\hline & \multicolumn{3}{|c|}{ Baseline } & \multirow{2}{*}{$\mathrm{p}$-value } & \multicolumn{3}{|c|}{ The last follow-up } & \multirow{2}{*}{$\mathrm{p}$-value } \\
\hline & $\mathrm{N}$ & $\mathrm{E}$ & $P$ & & $\mathrm{~N}$ & $\mathrm{E}$ & $\mathrm{P}$ & \\
\hline \multicolumn{9}{|c|}{ Mucosal atrophy } \\
\hline Antrum & 0.92 & 1.05 & 1.17 & 0.224 & 1.16 & 1.43 & 1.27 & 0.183 \\
\hline \multirow[t]{2}{*}{ Corpus } & 0.76 & 1.05 & 1.13 & $0.025\left(\mathrm{~N}\right.$ vs E) ${ }^{*}$ & 0.78 & 1.08 & 1.28 & $0.001(\mathrm{~N} \text { vs } \mathrm{P})^{*}$ \\
\hline & & & & $0.011(\mathrm{~N} \text { vs } \mathrm{P})^{*}$ & & & & \\
\hline \multicolumn{9}{|c|}{ Intestinal metaplasia } \\
\hline Antrum & 1.48 & 1.58 & 1.56 & 0.562 & 1.71 & 1.74 & 1.67 & 0.844 \\
\hline Corpus & 1.25 & 1.34 & 1.39 & 0.616 & 1.13 & 1.34 & 1.24 & 0.302 \\
\hline
\end{tabular}

Data are presented as mean.

Kruskal-Wallis test. Patients with no precancerous lesion numbered 0; mild 1; moderate 2; and marked 3 based on the updated Sydney system. $\mathrm{N}$, negative group; E, eradicated group; $\mathrm{P}$, persistent group.

*Mann-Whitney U test on each pair of groups.

Table 5. Risk Factors for the Development of Metachronous Cancer

\begin{tabular}{lccc}
\hline \multicolumn{1}{c}{ Variable } & HR & 95\% CI & p-value \\
\hline Age (each incremental year) & 1.059 & $1.001-1.120$ & 0.045 \\
Male (female-reference) & 2.827 & $0.654-12.216$ & 0.164 \\
Antral mucosal atrophy (each incremental grade) & 1.578 & $0.920-2.706$ & 0.098 \\
Corpus mucosal atrophy (each incremental grade) & 0.790 & $0.469-1.330$ & 0.375 \\
Antral intestinal metaplasia (each incremental grade) & 0.743 & $0.440-1.254$ & 0.267 \\
Corpus intestinal metaplasia (each incremental grade) & 1.453 & $0.915-2.308$ & 0.113 \\
Negative group (persistent group-reference) & 1.583 & $0.629-3.985$ & 0.330 \\
Eradicated group (persistent group-reference) & 0.862 & $0.309-2.402$ & 0.776 \\
\hline
\end{tabular}

HR, hazard ratio; CI, confidence interval.

proportions of patients with antral mucosal atrophy and intestinal metaplasia. Many studies reported different results concerning the changes in precancerous lesions after $H$. pylori eradica- tion. ${ }^{5-10}$ The most important reason for discrepant results among previous studies might be the difference in the study population. In this study, antral mucosal atrophy and intestinal metaplasia 
were irreversible by $H$. pylori eradication after endoscopic resection of EGC.

During the follow-up period, metachronous cancer had developed in $8.8 \%$ of patients, which did not differ significantly between the groups. In a prospective study, H. pylori eradication had reduced the incidence of gastric cancer only in the subgroup without precancerous lesions. ${ }^{17}$ Another study reported that $H$. pylori eradication appeared to reduce the incidence of gastric cancer in patients without baseline precancerous gastric lesions. ${ }^{18}$ We previously reported that $H$. pylori eradication did not reduce the incidence of metachronous gastric lesions after endoscopic resection of EGC. ${ }^{13}$ These results suggest that $H$. pylori eradication might not prevent metachronous lesions in patients with precancerous lesions or cancer.

In subgroup analyses of younger patients, Kaplan-Meier analysis showed that the cumulative incidence rate of metachronous cancer development was lower in the eradicated group than in the persistent and the negative groups. The difference of metachronous cancer development in the Kaplan-Meier curves was widened at a follow-up period of 72 to 84 months, and continued to widen thereafter. The mean histological grades of the corpus mucosal atrophy were not different between the negative and the eradicated groups at the last follow-up in subgroup of younger patients. Considering the eradicated group showed significantly higher histological grade than the negative group at baseline in this subgroup, this indicate that $H$. pylori eradication may prevents the long-term development of metachronous cancer in younger patients by delaying the progression of precancerous lesions.

Although $H$. pylori infection was reported as a risk factor of metachronous cancer development, ${ }^{14,19,20}$ the cumulative incidence rate of metachronous cancer was higher in the negative group than in the eradicated group for all patients and patients aged less than 70 years in this study. The mean age in the negative group was higher than in the eradicated group, and age was an independent risk factor for metachronous cancer development in this study, which is consistent with previous studies. ${ }^{19,20}$ The difference in age might be the reason for the higher incidence of metachronous cancer development in the negative group than in the eradicated group.

Our study had several limitations. As previous history of $H$. pylori infection and eradication before the time of ESD could not be confirmed, the patients who had been treated for $H$. pylori infection before the time of ESD might be classified as the negative group. Also, selection bias may be the limitation by the non-randomization of $H$. pylori eradication and the retrospective manner although the baseline characteristics of patients did not differ among the groups except corpus mucosal atrophy. Nonetheless, the strength of our study was the long-term follow-up of precancerous lesions as well as metachronous cancer in unified patients.
In conclusion, $H$. pylori eradication might prevent the progression of corpus mucosal atrophy and reduce the incidence of metachronous cancer development in patients less than 70 years of age after endoscopic resection of EGC. Age was an independent risk factor for metachronous cancer development.

\section{CONFLICTS OF INTEREST}

No potential conflict of interest relevant to this article was reported.

\section{ACKNOWLEDGEMENTS}

This work was supported by Promising-Pioneering Researcher Program through Seoul National University (SNU) in 2015.

Author contributions: S.J.H. and S.G.K. carried out study design, data analysis, and interpretation. S.J.H. carried out manuscript drafting. J.H.L., J.M.C., S.O., J.Y.P., J.K., J.S.K., and H.C.J. participated in manuscript revision. All authors read and approved the final manuscript.

\section{REFERENCES}

1. World Health Organization (WHO). WHO statistical information system [Internet]. Geneva: WHO; c2017 [cited 2017 Feb 14]. Available from: http://www.who.int/mediacentre/factsheets/fs297/ en/.

2. Chung IK, Lee JH, Lee SH, et al. Therapeutic outcomes in 1000 cases of endoscopic submucosal dissection for early gastric neoplasms: Korean ESD Study Group multicenter study. Gastrointest Endosc 2009;69:1228-1235.

3. Isomoto H, Shikuwa S, Yamaguchi N, et al. Endoscopic submucosal dissection for early gastric cancer: a large-scale feasibility study. Gut 2009;58:331-336.

4. Correa P, Houghton J. Carcinogenesis of Helicobacter pylori. Gastroenterology 2007;133:659-672.

5. Rokkas T, Pistiolas D, Sechopoulos P, Robotis I, Margantinis G. The long-term impact of Helicobacter pylori eradication on gastric histology: a systematic review and meta-analysis. Helicobacter 2007;12 Suppl 2:32-38.

6. Wang J, Xu L, Shi R, et al. Gastric atrophy and intestinal metaplasia before and after Helicobacter pylori eradication: a metaanalysis. Digestion 2011;83:253-260.

7. Toyokawa T, Suwaki K, Miyake Y, Nakatsu M, Ando M. Eradication of Helicobacter pylori infection improved gastric mucosal atrophy and prevented progression of intestinal metaplasia, especially in the elderly population: a long-term prospective cohort study. J Gastroenterol Hepatol 2010;25:544-547.

8. Ito M, Haruma K, Kamada T, et al. Helicobacter pylori eradication therapy improves atrophic gastritis and intestinal metaplasia: a 5-year prospective study of patients with atrophic gastritis. Ali- 
ment Pharmacol Ther 2002;16:1449-1456.

9. Kong YJ, Yi HG, Dai JC, Wei MX. Histological changes of gastric mucosa after Helicobacter pylori eradication: a systematic review and meta-analysis. World J Gastroenterol 2014;20:5903-5911.

10. Ohkusa T, Fujiki K, Takashimizu I, et al. Improvement in atrophic gastritis and intestinal metaplasia in patients in whom Helicobacter pylori was eradicated. Ann Intern Med 2001;134:380-386.

11. Fukase K, Kato M, Kikuchi S, et al. Effect of eradication of Helicobacter pylori on incidence of metachronous gastric carcinoma after endoscopic resection of early gastric cancer: an open-label, randomised controlled trial. Lancet 2008;372:392-397.

12. Yoon SB, Park JM, Lim CH, Cho YK, Choi MG. Effect of Helicobacter pylori eradication on metachronous gastric cancer after endoscopic resection of gastric tumors: a meta-analysis. Helicobacter 2014;19:243-248.

13. Choi J, Kim SG, Yoon H, et al. Eradication of Helicobacter pylori after endoscopic resection of gastric tumors does not reduce incidence of metachronous gastric carcinoma. Clin Gastroenterol Hepatol 2014;12:793-800.e1.

14. Jung S, Park CH, Kim EH, et al. Preventing metachronous gastric lesions after endoscopic submucosal dissection through Helico- bacter pylori eradication. J Gastroenterol Hepatol 2015;30:75-81.

15. Japanese Gastric Cancer Association. Japanese classification of gastric carcinoma: 3rd English edition. Gastric Cancer 2011;14:101-112.

16. Stolte M, Meining A. The updated Sydney system: classification and grading of gastritis as the basis of diagnosis and treatment. Can J Gastroenterol 2001;15:591-598.

17. Wong BC, Lam SK, Wong WM, et al. Helicobacter pylori eradication to prevent gastric cancer in a high-risk region of China: a randomized controlled trial. JAMA 2004;291:187-194.

18. Fuccio L, Zagari RM, Minardi ME, Bazzoli F. Systematic review: Helicobacter pylori eradication for the prevention of gastric cancer. Aliment Pharmacol Ther 2007;25:133-141.

19. Kim YI, Choi IJ, Kook MC, et al. The association between Helicobacter pylori status and incidence of metachronous gastric cancer after endoscopic resection of early gastric cancer. Helicobacter 2014;19:194-201.

20. Kwon YH, Heo J, Lee HS, Cho CM, Jeon SW. Failure of Helicobacter pylori eradication and age are independent risk factors for recurrent neoplasia after endoscopic resection of early gastric cancer in 283 patients. Aliment Pharmacol Ther 2014;39:609-618. 